\title{
Hydrothermal preparation of nanometer lithium nickel vanadium oxide powder at low temperature
}

\author{
Chung-Hsin Lu*, Shaw-Jang Liou \\ Department of Chemical Engineering, National Taiwan University Taipei, Taipei, Taiwan, ROC
}

Received 8 August 1999; received in revised form 13 December 1999; accepted 14 January 2000

\begin{abstract}
A new hydrothermal process has been developed in this study for synthesizing nanometer $\mathrm{LiNiVO}_{4}$ powder. It was found that when using distilled water as solvent, $\mathrm{LiNiVO}_{4}$ cannot be obtained, and different types of unidentified products are formed. On the other hand, when isopropanol is used, $\mathrm{LiNiVO}_{4}$ powder can be successfully prepared. In comparison with the conventional process, the new hydrothermal process significantly lowers the required reaction temperature and reduces the size of formed particles. In the new process, the required temperature for preparing $\mathrm{LiNiVO}_{4}$ is reduced to $200^{\circ} \mathrm{C}$, and the particle size is decreased to nanometer. The crystallinity of $\mathrm{LiNiVO}_{4}$ can be improved by increasing the hydrothermal temperature and adding ammonia carbonate. (C) 2000 Elsevier Science S.A. All rights reserved.
\end{abstract}

Keywords: LiNiVO4; Water; Solvent; Crystallinity

\section{Introduction}

Recently, a variety of solution techniques have been developed in order to synthesize ceramic powder with fine particle size and well-controlled morphology. In general, aqueous or organic-based solutions containing appropriate cations are prepared first. The cations are either precipitated by adding reactants to form precipitates in the precipitation process, or are condensed and polymerized to form gel-like precursors in the sol-gel process. Neither of the above two processes can always produce the resultant precursors with the required crystal structure of ceramics. Therefore, subsequent calcination at elevated temperatures are needed to facilitate the complete formation of precursors. On the other hand, the hydrothermal process has been found to be an effective method which can directly synthesize the crystalline ceramic powder from solution [1-6]. Thus, not only does this process avoid the undesired calcination processes, but also significantly reduces both the particle size of powder and the synthesis temperatures. Accordingly, the hydrothermal process makes the formation of nanometer ceramic particles to become feasible.

\footnotetext{
* Corresponding author.
}

Lithium nickel vanadium oxide $\left(\mathrm{LiNiVO}_{4}\right)$ is known as a potential cathode material for its use in the lithium ion secondary batteries. This material exhibits a very high voltage (up to $4.8 \mathrm{~V}$ ) in lithium cells [7]; however, synthesizing $\mathrm{LiNiVO}_{4}$ is a difficult process, since it requires heating at elevated temperatures for several days when using solid-state reaction [8-10]. The particle size of the obtained powder is around $20 \mu \mathrm{m}$ [10]. Whereas in the solution process, the synthesis time can be reduced to $2 \mathrm{~h}$, and the particle size is decreased to be less than $1 \mu \mathrm{m}$; however, the synthesis temperature has to be not lower than $500^{\circ} \mathrm{C}$ [11]. If the particle size of $\mathrm{LiNiVO}_{4}$ can be reduced to be nanometer, the electrochemical activity and the charge/discharge efficiency of $\mathrm{LiNiVO}_{4}$ in lithium-ion batteries shall be significantly improved. In order to synthesize the nanometer $\mathrm{LiNiVO}_{4}$ powder and reduce its synthesis temperature, a novel hydrothermal process was developed in this study. Two different solvents: viz. water and isopropanol were used $\mathrm{m}$ the hydrothermal reactions. The effects of solvents and starting materials on the resulting products were examined. In addition, for improving the crystallinity of $\mathrm{LiNiVO}_{4}$ powder, the influence of different types of additives on the formation and the microstructure of $\mathrm{LiNiVO}_{4}$ was also studied. 


\section{Experimental}

In order to vary the reactivity of species in the hydrothermal reaction, different types of starting materials, viz. lithium hydroxide, lithium carbonate, nickel hydroxide, nickel acetate, nickel nitrate, vanadium oxide, and ammonium vanadium were utilized. Distilled water and isopropanol were each used as solvents in hydrothermal reactions in the first and second parts of the experiment, respectively. The starting materials were added into distilled water or isopropanol at a molar ratio of $\mathrm{Li}^{1+}: \mathrm{Ni}^{2+}: \mathrm{V}^{5+}=1: 1: 1$, and heated in a teflon-lined autoclave apparatus at temperature ranging from 150 to $230^{\circ} \mathrm{C}$ for $1-6 \mathrm{~h}$. The concentration of

Table 1

Products formed in the hydrothermal reaction when distilled water is used as solvent

\begin{tabular}{|c|c|c|c|}
\hline $\begin{array}{l}\text { Run } \\
\text { number }\end{array}$ & $\begin{array}{l}\text { Starting } \\
\text { materials }\end{array}$ & $\begin{array}{l}\text { Reaction } \\
\text { conditions }\end{array}$ & Products \\
\hline A1 & $\begin{array}{l}\mathrm{Ni}(\mathrm{OH})_{2}, \mathrm{LiOH}, \\
\mathrm{V}_{2} \mathrm{O}_{5}\end{array}$ & $200^{\circ} \mathrm{C} / 2 \mathrm{~h}$ & $\begin{array}{l}x \text {-phase, } \\
\mathrm{Ni}(\mathrm{OH})_{2}\end{array}$ \\
\hline A2 & $\begin{array}{l}\mathrm{Ni}(\mathrm{OH})_{2}, \mathrm{Li}_{2} \mathrm{CO}_{3}, \\
\mathrm{~V}_{2} \mathrm{O}_{5}\end{array}$ & $200^{\circ} \mathrm{C} / 2 \mathrm{~h}$ & $\begin{array}{l}x \text {-phase, } \\
\mathrm{Ni}(\mathrm{OH})_{2}\end{array}$ \\
\hline A3 & $\begin{array}{l}\mathrm{Ni}(\mathrm{OH})_{2}, \mathrm{LiOH} \\
\mathrm{NH}_{4} \mathrm{VO}_{3}\end{array}$ & $200^{\circ} \mathrm{C} / 2 \mathrm{~h}$ & $\begin{array}{l}x \text {-phase, } \\
\mathrm{Ni}(\mathrm{OH})_{2}\end{array}$ \\
\hline A4 & $\begin{array}{l}\mathrm{Ni}(\mathrm{OH})_{2}, \mathrm{~L}_{2} \mathrm{CO}_{3}, \\
\mathrm{NH}_{4} \mathrm{VO}_{3}\end{array}$ & $200^{\circ} \mathrm{C} / 2 \mathrm{~h}$ & $\begin{array}{l}x \text {-phase, } \\
\mathrm{Ni}(\mathrm{OH})_{2}\end{array}$ \\
\hline A5 & $\begin{array}{l}\mathrm{Ni}\left(\mathrm{C}_{2} \mathrm{H}_{3} \mathrm{O}_{2}\right)_{2}, \mathrm{LiOH} \\
\mathrm{V}_{2} \mathrm{O}_{5}\end{array}$ & $200^{\circ} \mathrm{C} / 2 \mathrm{~h}$ & $x$-phase \\
\hline A6 & $\begin{array}{l}\mathrm{Ni}\left(\mathrm{NO}_{3}\right)_{2}, \mathrm{LiOH} \\
\mathrm{V}_{2} \mathrm{O}_{5}\end{array}$ & $200^{\circ} \mathrm{C} / 2 \mathrm{~h}$ & $y$-phase \\
\hline
\end{tabular}

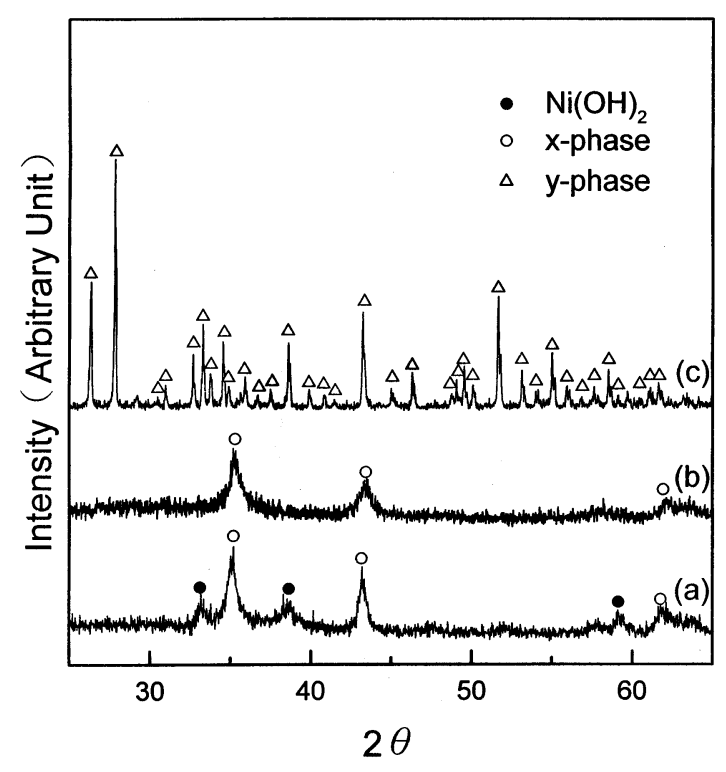

Fig. 1. X-ray diffraction patterns of the powder obtamed in runs (a) A1; (b) A5 and (c) A6. the total added cations was adjusted to $0.3-0.6 \mathrm{M}$. During the hydrothermal reaction, a mechanical stirrer was used at a rotation speed of $200 \mathrm{rpm}$. After the hydrothermal reaction, the obtained products were filtered, washed, and dried. The compounds present in the powders were identified by a X-ray powder diffractometer (Mac Science, MXP3). The microstructural evolution and particle size of the powder were examined by a transmission scanning electron microscope (Hitachi, H-7100). Infrared spectra of the samples were recorded on an infrared spectrophotometer (Hitachi, 270-30).

\section{Results and discussion}

In the first part of the experiment, distilled water was used as solvent in the hydrothermal reaction. Different types of starting materials were added in distilled water, and heated under various hydrothermal conditions. Table 1 summaries the experimental conditions and the results of XRD analysis. In runs A1-A4, the source of nickel cations was prepared from nickel hydroxide, while lithium cations were obtained from lithium hydroxide or carbonate, and vanadium cations from vanadium oxide or ammonium vanadium. After heating at $200^{\circ} \mathrm{C}$ for $2 \mathrm{~h}$, these four runs resulted $\mathrm{m}$ similar crystalline products. The representative XRD pattern of the products in run $\mathrm{A} 1$ is shown in Fig. 1 (a). The obtained products contained a small amount of $\mathrm{Ni}(\mathrm{OH})_{2}$, and an unknown phase which could not be identified by comparing with the XRD patterns given in the JCPDS files. This unknown phase is termed as $x$-phase. It was noted that the types of starting materials used for lithium and vanadium cations did not significantly affect the formation of $x$-phase. When the products obtained by runs $\mathrm{A} 1-\mathrm{A} 4$ were calcined at $800^{\circ} \mathrm{C}$ for $2 \mathrm{~h}, \mathrm{NiO}$ and a small amount of $\mathrm{LiNiVO}_{4}$ were formed. Thus, calcining the hydrothermallyderived products could not yield pure $\mathrm{LiNiVO}_{4}$ powder.

In runs $\mathrm{A} 5$ and $\mathrm{A} 6$, lithium hydroxide and vanadium oxide were used as the sources of lithium and vanadium cations, while nickel cations were obtained from nickel acetate and nickel nitrate. The XRD patterns of the products formed in these two runs are presented in Fig. 1(b) and (c). The product of run A5 is $x$-phase as well, while that of run A6 is another unknown compound, $y$-phase. When y-phase was calcined at $800^{\circ} \mathrm{C}$ for $2 \mathrm{~h}$, $\mathrm{Ni}_{2} \mathrm{~V}_{2} \mathrm{O}_{7}$ and $\mathrm{V}_{2} \mathrm{O}_{5}$ were produced, implying that the composition of y-phase contains nickel and vanadium species, but no lithium species. It is found that the above experiments failed to yield pure $\mathrm{LiNiVO}_{4}$ by either the hydrothermal reactions or calcination processes.

In a previous study [12], it is found that $\mathrm{LiVO}_{3}$ is formed as an intermediate compound during the forma- 


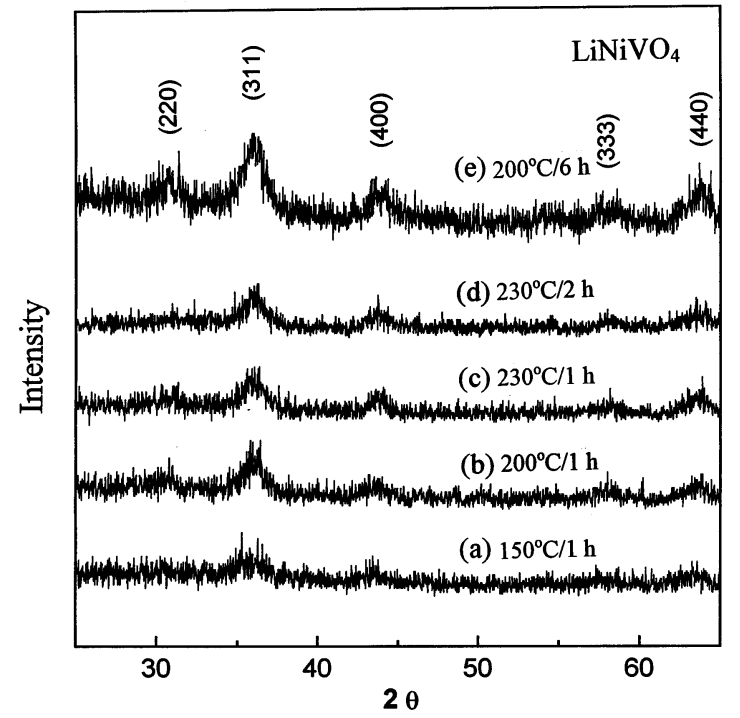

Fig. 2. X-ray diffraction patterns of the powder prepared by hydrothermal reactions at different conditions. The solvent used is isopropanol, and the starting materials are lithium hydroxide, nickel acetate, and vanadium oxide.

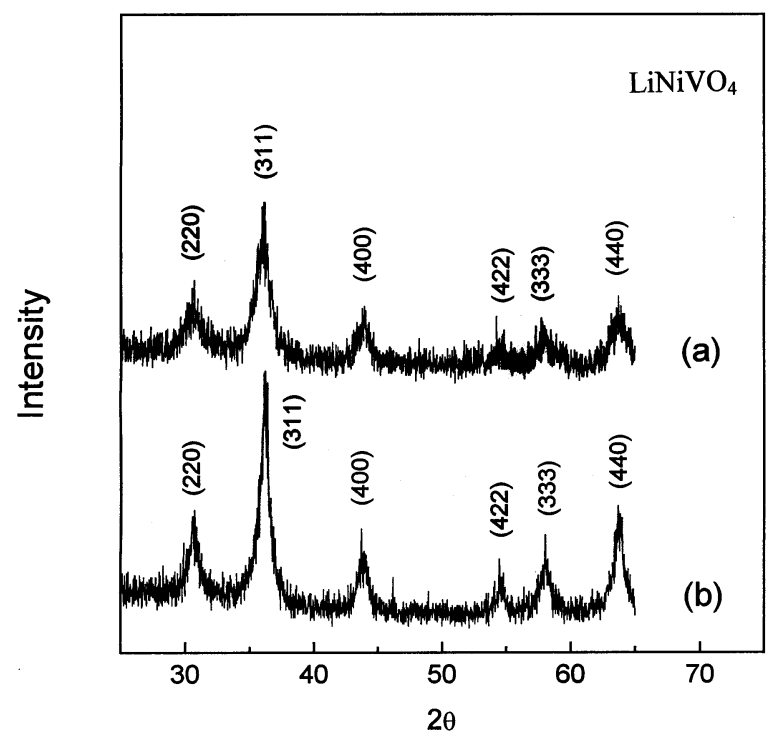

Fig. 3. X-ray diffraction patterns of the powder prepared by hydrothermal reactions at $200^{\circ} \mathrm{C}$ using isopropanol as solvent. The starting materials in (a) are lithium hydroxide, nickel acetate, and ammonium vanadium, and in (b) are lithium hydroxide, nickel acetate, vanadium oxide, and ammonium carbonate.

tion of $\mathrm{LiNiVO}_{4}$ in solid-state reaction. When $\mathrm{LiVO}_{3}$ reacts completely with $\mathrm{NiO}$, pure $\mathrm{LiNiVO}_{4}$ is produced. On the other hand, $\mathrm{LiVO}_{3}$ is not formed in the present hydrothermal reaction, since it is water-soluble. Therefore, changing the solvent was considered to be a worthwhile approach for preparing pure $\mathrm{LiNiVO}_{4}$. Thus, in the second part of the experiment, isopropanol was used as solvent to replace distilled water in the hydrothermal reaction. When lithium hydroxide and vanadium oxide reacted with nickel nitrate, an amorphous product was obtained. However, when nickel acetate was used instead of nickel nitrate, $\mathrm{LiNiVO}_{4}$ was formed. It seems that the $\mathrm{NO}_{3}^{-}$anions in nickel nitrate impede the crystallization of $\mathrm{LiNiVO}_{4}$. The effects of reaction temperature and time on the formation of $\mathrm{LiNiVO}_{4}$ are shown m Fig. 2. After heating at $150^{\circ} \mathrm{C}$ for $1 \mathrm{~h}$, a small diffraction peak, indexed as (311), was observed. With an increase in the heating temperature, the diffraction pattern of $\mathrm{LiNiVO}_{4}$ became clear. When $200^{\circ} \mathrm{C}$-heating was prolonged to $6 \mathrm{~h}$, the intensity of the diffraction peaks belonging to $\mathrm{LiNiVO}_{4}$ further increased.

Increasing both reaction temperature and reaction time were found to have a positive effect on the formation of $\mathrm{LiNiVO}_{4}$. However, the crystal structure of $\mathrm{LiNiVO}_{4}$ was not yet well developed. Subsequently, $\mathrm{NH}_{4} \mathrm{VO}_{3}$ was used to substitute $\mathrm{V}_{2} \mathrm{O}_{5}$, and it was found that the $\mathrm{NH}_{4} \mathrm{VO}_{3}$ possessed a higher reactivity than $\mathrm{V}_{2} \mathrm{O}_{5}$. Well crystallized $\mathrm{LiNiVO}_{4}$ was thus obtained (see Fig. 3(a)), the XRD pattern of which was consistent with that given in the JCPDS File no. 38-1395 [13]. Therefore, the formation of $\mathrm{LiNiVO}_{4}$ powder was confirmed. In comparison with the previous solution processes [11], the hydrothermal process developed herein successfully reduces the synthesis temperature of $\mathrm{LiNiVO}_{4}$ from 500 to $200^{\circ} \mathrm{C}$. It is evident that the hydrothermal environment remarkably accelerates the reaction kinetics of the formation of $\mathrm{LiNiVO}_{4}$. The infrared spectra of as-prepared $\mathrm{LiNiVO}_{4}$ powder is shown in Fig. 4 (a). The band at $3500 \mathrm{~cm}^{-1}$ is characteristic of the $\mathrm{O}-\mathrm{H}$ group, and those at 1600 and 1450 $\mathrm{cm}^{-1}$ result from the absorption of $\mathrm{C}=\mathrm{O}$ group [14]. The band at $1000-600 \mathrm{~cm}^{-1}$ is characteristic of the

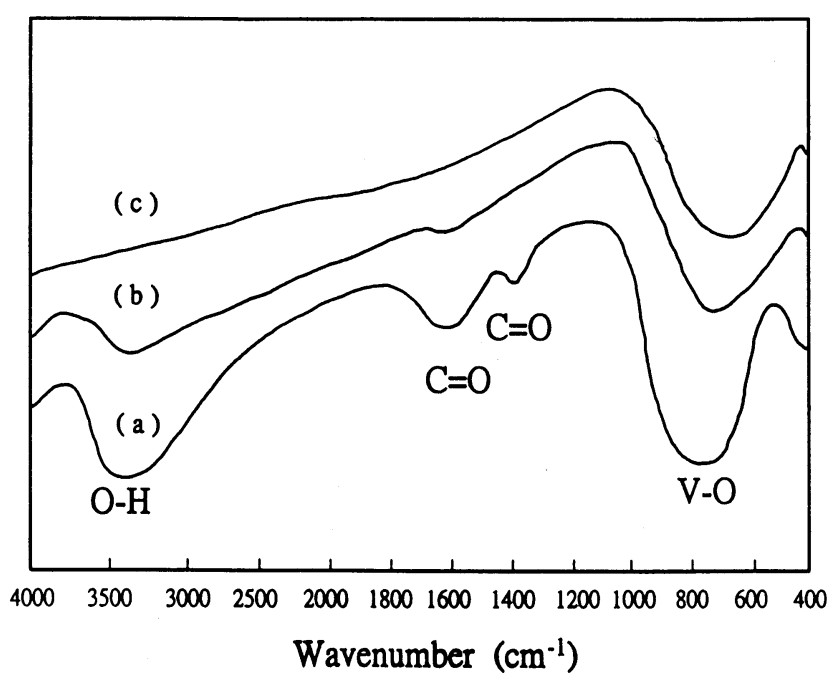

Fig. 4. (a) Infrared spectrum of $\mathrm{LiNiVO}_{4}$ powder prepared by hydrothermal reactions at $200^{\circ} \mathrm{C}$ using isopropanol as solvent. (b) and (c) are infrared spectra of the hydrothermally derived $\mathrm{LiNiVO}_{4}$ powder calcined at $400^{\circ} \mathrm{C}$ and $700^{\circ} \mathrm{C}$ for $2 \mathrm{~h}$, respectively. 

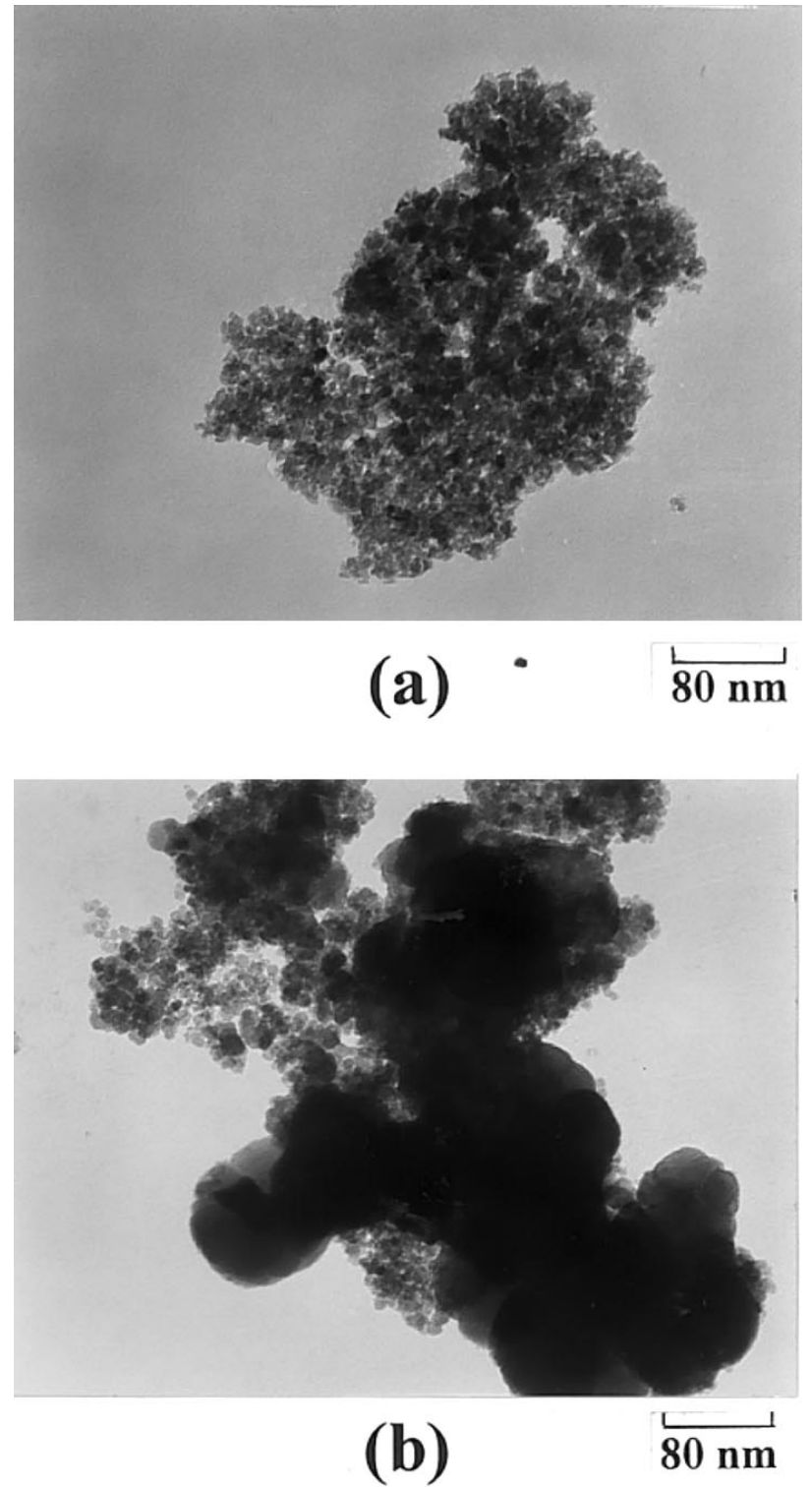

Fig. 5. Both (a) and (b) are transmission electron micrographs of hydrothermally derived $\mathrm{LiNiVO}_{4}$ powder shown in Fig. 3(a, b), respectively.

$\mathrm{V}-\mathrm{O}$ bonds of $\mathrm{VO}_{4}$ tetrahedron [15]. The presence of the organic remnants is probably originated from nickel acetate, the starting reagent. The residual organic groups are considered to hinder the progress of the crystallization of $\mathrm{LiNiVO}_{4}$. With a rise in the calcination temperature, the absorption intensities of the $\mathrm{C}=\mathrm{O}$ and $\mathrm{O}-\mathrm{H}$ groups significantly decrease. After heating at $700^{\circ} \mathrm{C}$, only the $\mathrm{V}-\mathrm{O}$ bonds exist in the specimen (see Fig. 4(c)).

In order to further improve the crystallinity of $\mathrm{LiNiVO}_{4}$, different types of additives were added in the isopropanol solution. Ammonia, $\mathrm{KOH}$, and citric acid were found to have an adverse effect on the crystallization and formation of $\mathrm{LiNiVO}_{4}$, since only amorphous products were obtained with the addition of these additives. On the other hand, when a small amount of ammonium carbonate $(0.2 \mathrm{M})$ was added in isopropanol, the crystallization of $\mathrm{LiNiVO}_{4}$ was accelerated (see Fig. 3(b)). The effect of ammonia carbonate on the crystallization process of $\mathrm{LiNiVO}_{4}$ is not clear right now. The variation in $\mathrm{pH}$ or the surface chemistry on particles caused by adding ammonia carbonate is considered to be the possible reason for the above behavior. The TEM micrographs of the thus obtained $\mathrm{LiNiVO}_{4}$ powder are shown in Fig. 5. As seen in Fig. 5(a), without the presence of ammonia carbonate, the particle size of $\mathrm{LiNiVO}_{4}$ powder is around $10 \mathrm{~nm}$; however, the addition of ammonia carbonate induces some $\mathrm{LiNiVO}_{4}$ particles to increase their size to be around $90 \mathrm{~nm}$ (see Fig. 5(b)). In either above case, nanometer $\mathrm{LiNiVO}_{4}$ powder has been successfully prepared in this study. The particle size of the above powder is considerably smaller than that of the powder prepared by either the conventional solid-state reaction [4] or the solution process [11]. Consequently, the hydrothermal process developed in this study not only successfully reduces the temperature for synthesizing $\mathrm{LiNiVO}_{4}$ to $200^{\circ} \mathrm{C}$, but also decreases its particle size to nanometer.

\section{Conclusions}

Hydrothermal reactions for synthesizing $\mathrm{LiNiVO}_{4}$ powder under various conditions including different types of starting materials, solvents, heating temperature, and reaction time, have been investigated. Using distilled water as solvent yields different kinds of unidentified compounds, but could not produce $\mathrm{LiNiVO}_{4}$. When isopropanol is used as solvent, $\mathrm{LiNiVO}_{4}$ powder is successfully synthesized. The crystallinity of $\mathrm{LiNiVO}_{4}$ is improved by increasing the hydrothermal temperature and adding ammonia carbonate. The hydrothermal process not only reduces the temperature for synthesizing pure $\mathrm{LiNiVO}_{4}$ to $200^{\circ} \mathrm{C}$, but also decreases its particle size. Nanometer $\mathrm{LiNiVO}_{4}$ powder has been synthesized by the newly developed process in this study.

\section{Acknowledgements}

The authors would like to acknowledge Chih-Yuan Tang and Miss Ching-Yen Lin in Advanced Instrument Center in National Taiwan University for helping to analyze the microstructure of prepared powder.

\section{References}

[1] R. Roy, J. Solid State Chem. 111 (1994) 11.

[2] A.T. Chien, J.S. Speck, F.F. Lange, A.C. Daykin, C.G. Levi, J. Mater. Res. 10 (1995) 1784. 
[3] C.H. Lu, N. Chyl, Mater. Lett. 29 (1996) 101.

[4] C.H. Lu, S.Y. Lo, Mater. Res. Bull. 32 (1997) 371.

[5] J. Moon, T. Li, C.A. Randall, J.H. Adair, J. Mater. Res. 12 (1997) 189.

[6] C.H. Lu, S.Y. Lo, Mater. Lett. 34 (1998) 172.

[7] G.T.K. Fey, W. Li, J.R. Dahn, J. Electrochem. Soc. 141 (1994) 2279.

[8] J.C. Bernier, P. Poix, A. Michel, Bull. Soc. Chim. France (1963) 1661.
[9] Y. Ito, Nippon Kagaku Kaishi 111 (1979) 1483.

[10] G.T.K. Fey, W.B. Perng, Mater. Chem. Phys. 47 (1997) 279.

[11] C.H. Lu, S.J. Liou, J. Mater. Sci. Lett. 17 (1998) 733.

[12] C.H. Lu, S.J. Liou, Ceram. Inter. 25 (1999) 431.

[13] Powder diffraction file, Card No. 3 8-13 95, Joint Committee on Powder Diffraction Standards, Swarthmore, PA.

[14] P. Barboux, J.M. Tarascon, F.K. Shokoohi, J. Solid State Chem. 94 (1991) 185.

[15] A.F. Corsnut, G. Blasse, Chem. Phys. Lett. 20 (1973) 347. 